\title{
9
}

\section{Manufacturing strategy assessment for enterprise integration}

\author{
Reini Bemelman and Dennis Jarvis \\ CSIRO Division of Manufacturing Technology, P.O. Box 4, Woodville \\ Sth. Aust., 5011, Australia. \\ reb@adl.dmt.csiro.au,dhj@adl.dmt.csiro.au
}

\begin{abstract}
Existing approaches to Enterprise Integration are limited in what they have to say about the strategic planning process which should precede any major change, such as Enterprise Integration, Business Process Re-engineering, adoption of Cellular Manufacturing, etc. Based on our experiences in successfully transforming manufacturing activities to Cellular Manufacturing, we suggest that it is indeed feasible to construct a methodology to support manufacturing strategy assessment, and that the tools and techniques that we used in analysing the existing environments prior to introducing Cellular Manufacturing could form the basis for such a methodology.
\end{abstract}

strategy formulation, cellular manufacturing

\section{Keywords}

\section{INTRODUCTION}

Faced with the pressures of ever increasing competition on a global scale manufacturers, more often than not, in sheer desperation or because of lack of an overall plan, are chasing the plethora of 3 letter acronym tools and techniques (JIT, TQM, TQC, SPC, MRP, CAD, CAM, QFD, FTA, FBD, DoE, MAE, PAE etc.) not only as a means to an end but sadly also as an end in itself. It has been the authors' experience that in industry today, there is little if any perception of the underlying commonality and connectivity between these tools and techniques. Paradoxically, the pursuit of acronyms often results in nett increased burden and hence can make survival more difficult. 
One of the major reasons for this dilemma is that while senior management are charged with "determining a destination and then plotting the course", they are often unaware of what is required in manufacturing system terms to support the path that they choose. How many senior managers know anything about MAP, TOP, IGES, CIM-OSA, group technology, fundamentals of MRP-II or indeed even manufacturing strategy formulation? Whilst this dichotomy continues, vendors (consultants and software providers) will continue to be allowed to "push their own barrow" and contribute to the propagation of "islands of opportunism". Warnecke (1993) states that from the debates in industrial management circles it can be seen that there is a growing need for new direction.

Enterprise Integration (EI) attempts to provide a framework which will facilitate closing this gap and provide "the new direction" through a structured methodology for designing and implementing Computer Integrated Manufacturing (CIM) systems. An initial survey of the literature points to well known frameworks such as CIM-OSA, GRAI-GIM and the Purdue Enterprise Reference Architecture (PERA). Further investigation however reveals that there are a multitude of proposed architectures and models in both the open and proprietary literature which purport to illustrate, explain and guide the task of integrating manufacturing activities and enterprises (Williams et al, 1994). Most of these reference architectures do however share the 4 basic architectural principles (Williams, 1991):

1. Abstraction

2. Modularity

3. Open-Endedness

4. Isolation of user requirements from system implementation

Our inclination to view issues such as EI from a user rather than an academic perspective has lead us to the conclusion that the inherent levels of complexity and detail in most of the current EI architectures, is a problem which, if not tackled, will become a major impediment to acceptance by industry. Furthermore, we believe that a critical success factor underpinning the attainment of EI is the provision of appropriate and business-relevant architectural guidelines for the formulation of company-wide vision, strategy and policy and a methodology which will:

- Facilitate effective and efficient project management

- Facilitate the determination of alternative implementation strategies based on a holistic view which incorporates and integrates technology, information and human beings

- Assist in the selection of the most appropriate implementation path

- Guide the design process in an orderly and structured fashion from conceptual design through to implementation and operation. Each phase should have predefined objectives, inputs, deliverables and an activity roadmap for achieving objectives

- Itself be evolving over time e.g. through incorporation of newly developed and appropriate tools and techniques

- Contain a rich assortment of usable tools and techniques to facilitate both the design and implementation / operation phases

- Facilitate the development and maintenance of a high-level organisational blueprint as a basis for evolutionary organisational development 
- Accommodate top-down, bottom-up and centre-out design and implementation methods.

At the present time, existing EI architectures provide only limited support for such a methodology and virtually no support for strategy formulation. What we propose in this paper is that successful transformation of manufacturing operations to cell-based manufacturing requires tools, techniques and strategies that not only address the above areas but complement existing EI architectures.

\section{THE CSIRO APPROACH TO FACILITY DESIGN}

In response to the limited scope of existing approaches to facility design and their inability to be applied to large problems, the CSIRO Division of Manufacturing Technology developed a new approach which takes into account the technical complexities inherent in the design of an effective Cellular Manufacturing environment (Wells et al., 1989; Bemelman and Jarvis, 1995). The approach, encapsulated in a suite of software programs which we have called the Facility Design Toolkit (FDT), is summarised below:

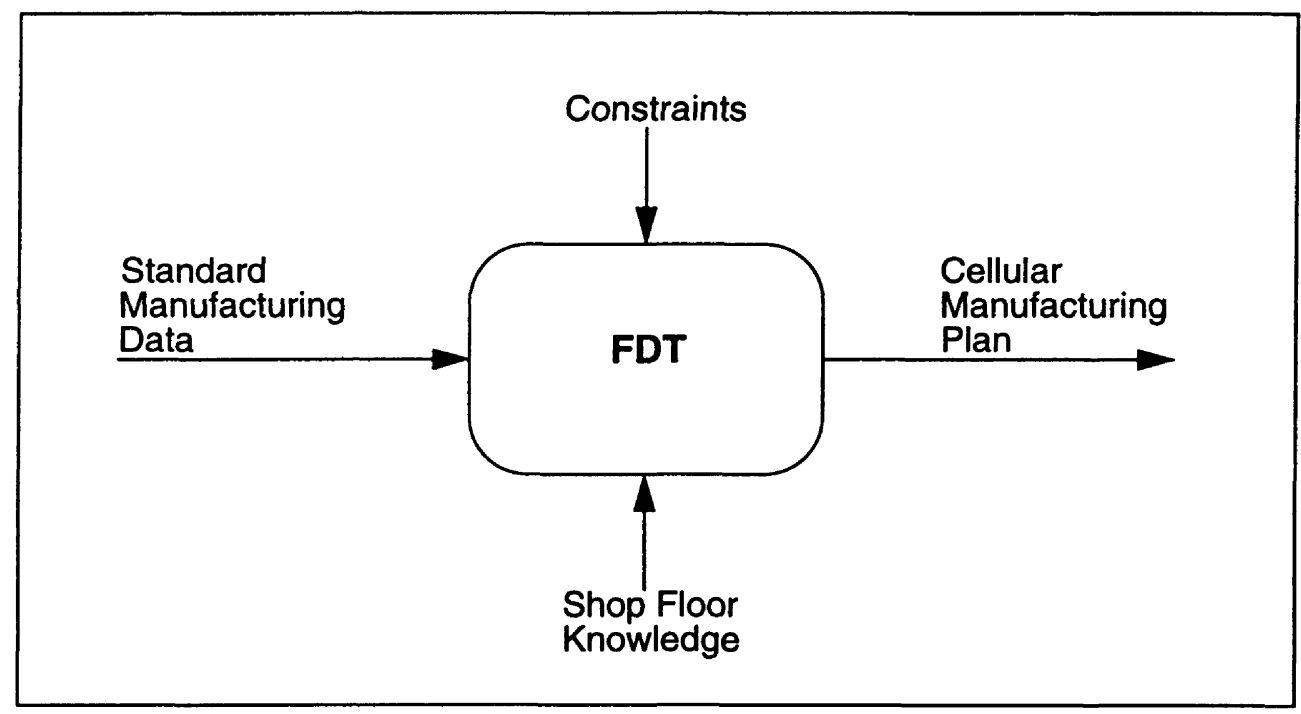

Figure 1 FDT Overview.

Note that FDT operates on standard manufacturing data in the form of Bills of Materials and Part Routes and relies heavily on manufacturing and industrial engineers and shop floor personnel to provide operational details and design objectives. FDT supports a top-down approach to cell design by partitioning the design process into the following steps:

1. Data Validation and Reformatting

2. Process Flow Analysis (PFA)

3. Cell Building

4. Load Balancing 


\section{Cell Testing}

Each phase has specific objectives, inputs and outputs. The level of detail increases as we move from PFA to the final phases of load balancing and cell testing, thus providing the ability to obtain an overview of the problem space early on in the design process. It is our belief such a capability is crucial when dealing with large problem sizes, such as those described in (Bemelman and Jarvis, 1995). The interested reader is referred to (Bemelman and Jarvis, 1995) for further details.

CSIRO DMT has been involved in a number of Facility Design projects in the plastics, automotive, aerospace and whitegoods industries (Bemelman and Jarvis, 1995). Given our lengthening track record with cellular implementations, it is only natural that our industrial partners are turning to us for advice and guidance on all relevant issues pertaining to what seems to be more akin to cultural and organisational change than with yet another acronym such as GT or CM! In the case of the plastics application, we were asked to address and audit their manufacturing planning and control systems. A recently completed project, which spanned several industrial sectors, looked beyond technical design to an appropriate partnership on the socio-technical front. In our most recent aerospace application, the company involved sought advice and assistance in strategy formulation, human resource issues, production planning and control issues and appropriate accountability and performance measures.

In the light of this experience, we have reassessed the role that the Facility Design Toolkit plays in the successful implementation of Cellular Manufacturing. In particular, we have observed that the scope of FDT needs to be extended both in terms of supporting more of the Facility Design lifecycle, and in addressing non-technical issues. We have proposed a lifecycle consisting of the following phases:
1. Preparation
2. Data Analysis
3. Resource Clustering
4. Physical Layout Planning
5. Virtual Cell Analysis
6. Installation
7. Operation
8. Redesign / Maintenance

FDT directly supports selected activities associated with the first 3 phases. In the course of our work, we have had to provide additional coverage for those phases, and to support the additional pre-installation phases. The activities for which we provide technical support are summarised below:

Phase 1: Preparation

- Create manufacturing base data and validate data

- Perform standard cross-file (data base) validation

- Establish a project database / log

- Provide background information and advice on implementation and on operating strategies

Phase 2: Data Analysis

- Provide access to packages for exploratory data analysis 
- Company Profiling

- Process Modelling

Phase 3: Resource Clustering

- Perform PFA, clustering and static load balancing.

- Evaluate individual cell designs by performing dynamic load balancing (with the aid of appropriate scheduling software such as described in (Lamacraft and Seabrook, 1993)).

Phase 4: Physical Layout Planning

- Use existing commercial packages

Phase 5: Virtual Cell Analysis

- Analyse the inter-cell traffic

- Analyse the performance of the entire cellular environment.

Where further support was required, the capabilities of FDT were augmented by the use of statistical packages, network analysis packages, data analysis programs constructed from standard Unix tools and standard systems analysis techniques. In addition to this direct technical support, the projects have required non-technical inputs, particularly in the area of Human Resources. We have also needed to consider such strategic issues as

- Is Cellular Manufacturing applicable to this environment?

- What will be the implications on other business processes within the enterprise (and vice versa)?

- How will the change process be managed?

When one steps back and observes Cellular Manufacturing in this light, it becomes obvious that there is considerable overlap between a successful implementation of Cellular Manufacturing and an Enterprise Integration exercise. Indeed, one could argue that if one applied the underlying principle of Cellular Manufacturing (i.e. the modularisation of manufacturing activities) to an enterprise, the outcome would be an integrated enterprise. Even if one does not subscribe to this view, the tools and techniques that we have developed are applicable throughout the entire Enterprise Integration process, and particularly at the strategy formulation phase.

In summary, we believe that from a company perspective, a successful transformation of manufacturing operations to a cellular manufacturing environment is an application of the principles of Enterprise Integration. It is assumed here that successful transformation implies totality of solution i.e. the problem is not simply viewed as a technical problem of regrouping parts and machines. The corollary to this is that we must be able to:

- Perform an initial assessment of a multiplicity of factors (technical, cultural and economic) to determine whether change can and should be undertaken. If it is decided that change should be undertaken, then we need to identify the company inputs required to facilitate the change process, an appropriate evolutionary path for change (i.e. top down, bottom up or centre-out) and suitable milestones.

- Facilitate change in either a top down, (e.g. full plant design) bottom up, (e.g. pilot cell design and implementation) or centre out (e.g. mini-factory design or parallel top down and bottom up design) direction.

- Focus on total employee involvement throughout the entire design life-cycle 
- Address all relevant human resource and organisational design issues including training, education, job design and nature of the supervisory organisational structure

- Evaluate current accountability and performance measures, highlight their deficiencies and suggest appropriate alternatives

- Provide an assessment of roles for support services and staff and degree of decentralisation

- Determine the most appropriate (ideal) physical plant(s) layout structure

- Simulate performance under a range of operating conditions

- Provide a mechanism for ongoing maintenance, assessment and change of revised operating methods and procedures

- Facilitate technology and methodology transfer to manufacturers

It is our belief that the construction of a methodology that supports the above objectives is indeed feasible and that we have accumulated some of the basic tools, techniques and strategies that are required. Moreover, we believe that such a methodology would provide significant leverage in the achievement of integration of manufacturing enterprises. Central to the use of such a methodology as the basis for achieving EI is the realisation that manufacturing should be the driver for change in manufacturing enterprises, and that by focusing on resources, we can provide tools and assistance in the modularisation of enterprises that is the likely outcome of an EI process.

\section{PREPARATION FOR CHANGE}

While we believe that the tools and techniques that we have developed to assist in the modularisation of manufacturing activities may ultimately be used in EI (and BPR) applications, we consider that the major benefit of our work is that we can provide a tangible set of tools and techniques that can be used in the preparation for change.

Our view of the change process implicit in Enterprise Integration is encapsulated in Figure 2. Our perception is that at the current time, reference architectures provide a framework for tackling the activities in both halves of the hourglass in Figure 2, but are much more focused on the bottom half, as evidenced by the following observations:

- In GERAM, "The coverage of the framework spans Products, Enterprises, Enterprise Integration and Strategic Enterprise Management, with the emphasis being on the middle two" (Nemes and Bernus, 1994).

- In CIM-OSA, it is assumed that the reasons for inititiating the project, the goals and objectives of the project and the scope of the project have been established prior to project initiation; their acquisition is not part of the CIM-OSA scope (Williams et al., 1994).

- GRAI-GIM's focus is restricted to the set of production system indicators (Doumeingts et al, 1992)

- PERA (Williams, 1991; Williams, 1994) stresses the need for determining organisational goals, objectives and critical success factors and includes aspects from Rockart's work on critical success factors (Rockart, 1979). However, it considers these aspects to be an interface to the process of Master Plan development (Williams, 1994). 
Furthermore, the support that is provided by the reference architectures is limited, particularly when viewed from the perspective of the cross-functional design teams that we believe are essential to facilitate major change.

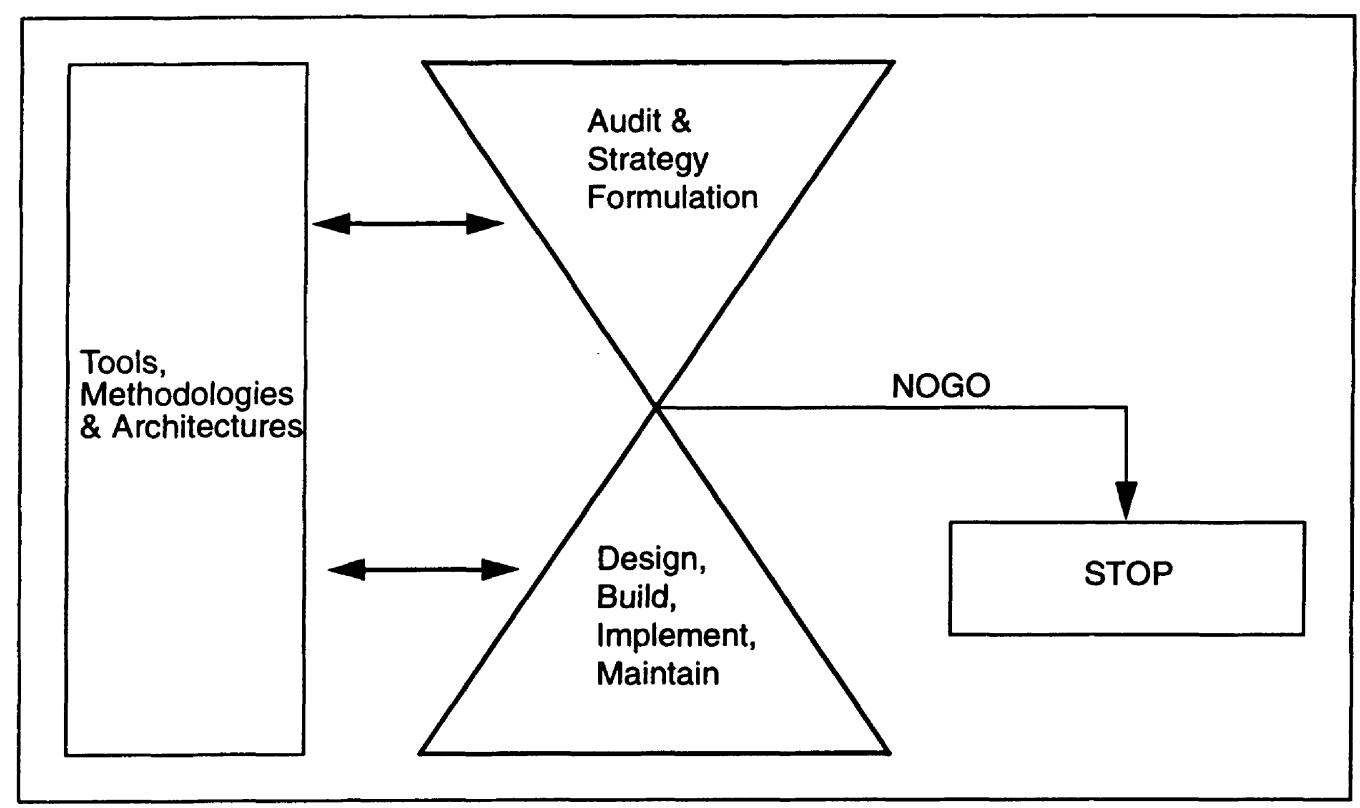

Figure 2 Simplified Change Process.

It is our belief that providing support for the apex of change - audit of status quo and strategy formulation is crucial to the acceptance of any major change process within an enterprise, be it adoption of Cellular Manufacturing, Enterprise Integration, Business Process Re-engineering or whatever. Furthermore, that support needs to provide outputs which are understandable by management. Most modern-day senior management is acutely aware of the inevitable competitive pressures and the need for change and new paradigms. Most, we would contend, also have some form of vision, albeit sketchy at times and possibly based on too narrow a scope of objectives, on repositioning their organisational units. For example, consider the following comments which have been made to us during the course of our involvement in Cellular Manufacturing implementations:

"We've always known that things could be improved, but that was based on gut feel - here you've clearly, objectively and quantifiably on one page highlighted the error of our ways. Now we can take some action based on facts".

"I agree with the concept of autonomous business units or self-contained factories and want the company to move in that direction. I have some vision (one page block diagram), but am not sure whether this can be justified or if more appropriate scenarios exist. Can your soft- 
ware help us untangle the spaghetti? Also, new CNC and other machines which are on order, will need to be considered".

"Why should the unions be involved at this stage; this is about reallocating machinery?"

"At what stage should we get shop-floor people involved?"

"Can you give a profile of the attributes required of a project leader?"

"What type of expertise do we need in our cell development team?"

"Should we start the process with full plant design or can this wait - why go with a pilot cell now - that's not going to give me the biggest bang for my buck!?"

"We are aware that the current method of applying a plant-wide overhead wrap-rate is inadequate. I guess we should move to activity based costing but that's a way off yet."

"Should we change the lead times in the corporate system for the parts that will be going into the new Group Technology cell?"

"What impact, if any, will decentralised tooling have?"

The point is that the mere fact these types of questions / issues are being raised is indicative of sound, or at the very least, active management thought processes with respect to change. We believe that these types of questions are symptomatic of a fundamental problem - the very things which elude today's manager can be summarised with metaphorical reference to Kipling's six honest men:

"What exactly is wrong (or could be improved), where is it wrong, why is it wrong, what are the options, how can change be brought about in an efficient and effective manner and what will this cost? Also, when (precedence and progression) should various changes take place and who should be involved."

The question now becomes: Can any of the reference architectures address Kipling's six honest men? Certainly, in their present form the answer has to be a resounding no! With the exception of PERA, there appears to be an implicit assumption that preparation for change has taken place prior to "engaging" the change process. If a fundamental requirement for any Enterprise Reference Architecture is that "It is necessary that all activities which are involved either directly or indirectly in designing and operating or improving the enterprise should be covered by the architecture" (Nemes and Bernus, 1994), then all relevant aspects of strategic planning should by definition be adequately supported. It seems appropriate therefore that an existing enterprise engineering methodology should be expanded to facilitate this fundamental process. As stated by Nemes and Bernus (1994), "the requisite methods need to be specified and (if possible) paradigmatic models should be incorporated". In this regard we would recommend further expansion of PERA possibly by incorporating relevant aspects of the analysis phase of GRAI-GIM (Doumeingts et al, 1992) or the strategic planning framework of (Hill, 1995). However, regardless of what approach is adopted, we believe that before change is initiated, a structured and comprehensive assessment of an organisation's status quo vis-a-vis market and corporate requirements should be undertaken by senior management. Assuming that problems are identified in this assessment, it will then proceed from identification of symptoms to the determination of underlying root causes en route to the preparation of an effective, efficient, responsive and competitive blueprint for the continuous development of manufacturing. The outcome of such a process must form the foundation for any subsequent 
re-engineering and / or integration efforts. Based on our experience in assessing and analysing enterprises with a view to implementing Cellular Manufacturing, we believe that the tools and techniques that we used and developed can form the basis of a successful methodology ${ }^{1}$.

There are obviously numerous components to such a methodology: architectural framework, diagnostic tools and techniques and interfacing with marketing and corporate strategy. The diagnostic component is critical and should facilitate the path from analysis to diagnosis and identification of symptoms through to determining root or fundamental causes for the symptoms. The outcome of the diagnostic component should be amenable to assessment and prioritisation based both on impact and perception of the organisation's current operating environment. The scope of the diagnostic should cover (as a minimum):

- Assessment of policy makers (senior management) and the strategic planning process

- Reality assessment of objectives and goals

- Evaluation of resource management - all company resources

- Audit of planning and control methods

- Assessment of innovation and improvement methodologies

- Determination of appropriateness of organisation structure and culture

- Assessment of interfaces (viz: inter- and intra-manufacturing function interfaces)

- Competitor / Industry Key Performance Indicators and benchmarking

In contrast, the change process in PERA begins with Master Plan development:

"The development of a Master Plan requires a comprehensive look at the business goals and critical success factors of an enterprise as well as a review and study of its processes, equipment, facilities, customer / market demands, personnel structure and roles, and the scheduling and control requirements (the enterprise integration component), among others. This results in a detailed plan, the Master Plan, to carry out the necessary coordination and integration action to provide enterprise integration for the factory, plant or other business entity" (Williams, 1994).

Emanating from the Master Plan is a document called the Enterprise Integration Program Proposal which lists a series of projects - all defined to be within the capability of the company - and includes a performance specification for each sub-project proposed (Williams, 1994). Note that PERA recognises that corporate strategy is crucial to the success of a change process, but it assumes that the strategy is already in place. This relationship is illustrated in Figure 3.

Master Plan Development corresponds to the concept, definition and functional design phases of PERA as outlined in (Williams, 1994). The subsequent phases are detailed functional design, construction, implementation and operation. The steps involved in the implementation of the Master Plan are summarised in (Williams, 1994); of particular interest is that PERA advocates that the definition of the to-be situation should precede analysis of the as-is situation.

\footnotetext{
1. We are currently involved in an experiment to determine whether frameworks and tools to support manufacturing strategy formulation in particular domains can be developed. Our focus thus far has been on the physical infrastructure reorganisation in a large, multi-plant discrete manufacturing site which produces 80,000 parts. Preliminary results are encouraging.
} 


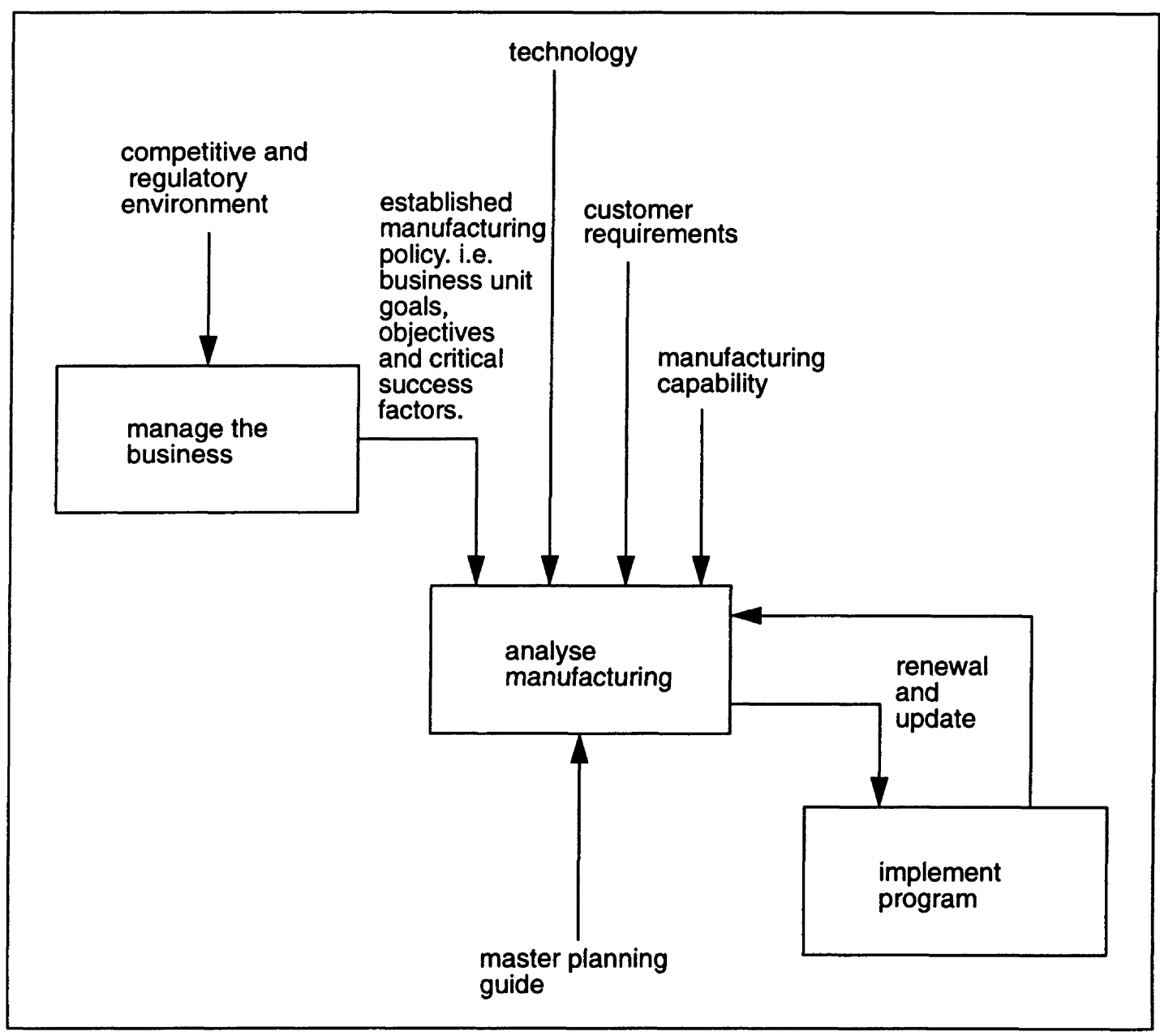

Figure 3 Relationship of the Established Manufacturing Policy, Guide to Master Planning and the Master Plan to each other (Williams, 1994).

The essential difference between our view of the change process and that of PERA is where one should start. Indeed, if we examine the architectural frameworks for PERA and our approach that are presented in Figure 4, it is apparent that the architectures are similar once a functional design has been developed. PERA assumes that corporate strategy has been determined prior to commencement of the change process; we would argue that strategy formulation is often an integral part of the change process. Some of the differences that arise from this different perspective are summarised in Table 1. 


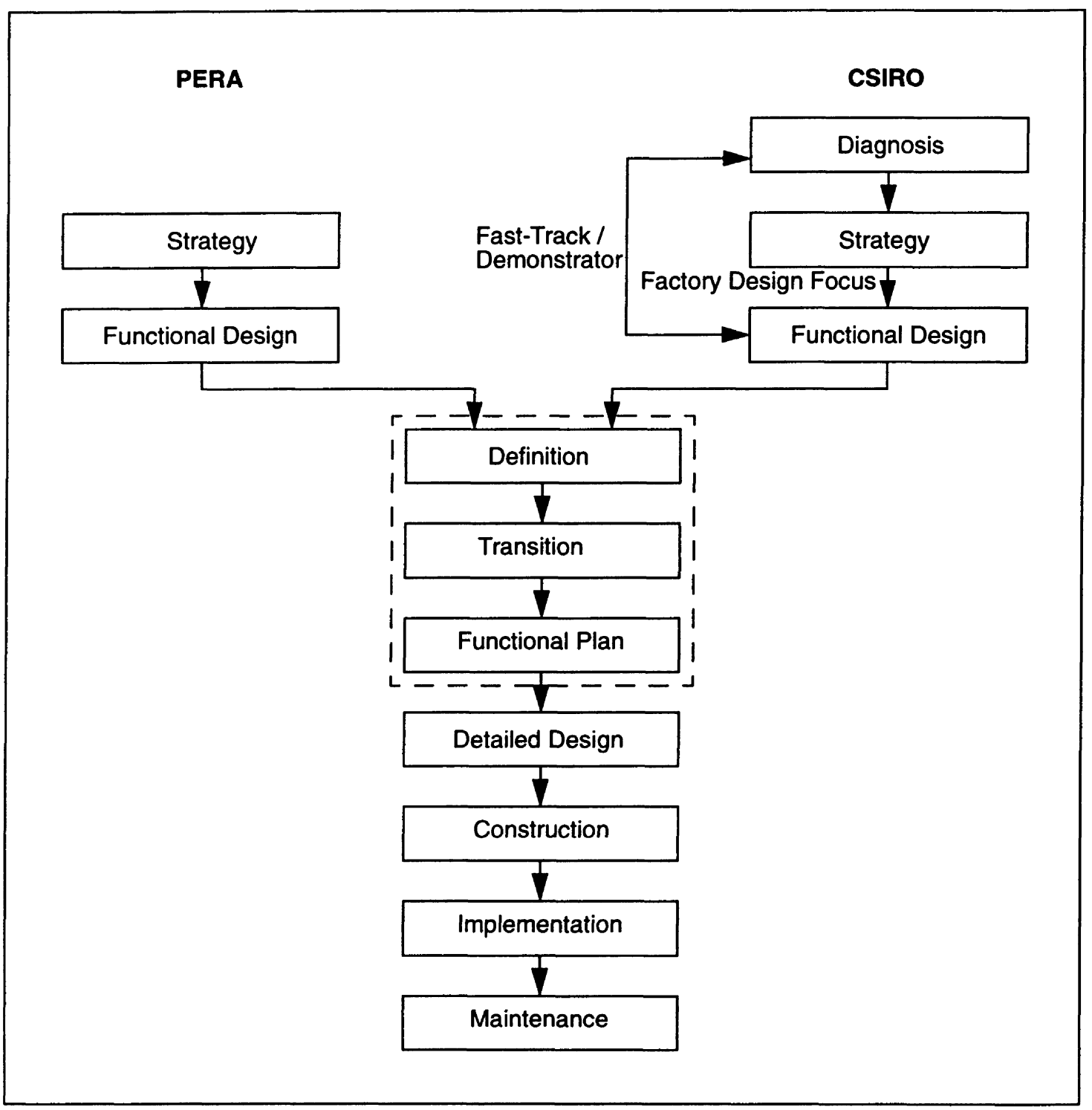

Figure 4 PERA vs. CSIRO architectural frameworks. 
Table 1: Some essential differences between the starting points for change for PERA and the CSIRO proposal.

\begin{tabular}{|c|c|}
\hline PERA - Master Plan Development & CSIRO Proposal \\
\hline $\begin{array}{l}\text { A foundation is an as-is understanding of: } \\
\text { - Plant information and control hierar- } \\
\text { chy. } \\
\text { - Process equipment; material, energy } \\
\text { and product flow associated with plant } \\
\text { layout. } \\
\text { - Personnel structures, functions and } \\
\text { roles. }\end{array}$ & $\begin{array}{l}\text { A foundation is an as-is understanding of: } \\
\text { - Human Resource and organisational } \\
\text { issues. } \\
\text { - Methods and Procedures. } \\
\text { - Money. } \\
\text { - Physical Assets (Plant, Inventory, etc.). } \\
\text { and their inter-relationships. Factory design } \\
\text { and resource management is included. }\end{array}$ \\
\hline $\begin{array}{l}\text { Master plan development covers the first } \\
\text { three phases of the PERA life cycle i.e. con- } \\
\text { cept, definition and functional design. }\end{array}$ & $\begin{array}{l}\text { CSIRO plan development covers the first } \\
\text { two phases of PERA life cycle. }\end{array}$ \\
\hline EI requires a manufacturing plan. & EI is a manifestation of strategic plans. \\
\hline $\begin{array}{l}\text { Preference for prerequisites for successful } \\
\text { implementations to be in place. }\end{array}$ & $\begin{array}{l}\text { Prerequisites for successful implementation } \\
\text { sought out and identified as a sub-project. }\end{array}$ \\
\hline Champion is a technologist. & Champion is a business "physician". \\
\hline $\begin{array}{l}\text { Focus on problems amenable to solution by } \\
\text { Enterprise Integration. }\end{array}$ & $\begin{array}{l}\text { Focus on uncovering ALL problems and } \\
\text { then finding ANY appropriate methodolo- } \\
\text { gies for solution. }\end{array}$ \\
\hline $\begin{array}{l}\text { Tacit assumption that the initiating sponsor } \\
\text { is a visionary. }\end{array}$ & $\begin{array}{l}\text { Initiating sponsor is subject to audit to help } \\
\text { align this person's view of the world with } \\
\text { reality. }\end{array}$ \\
\hline $\begin{array}{l}\text { The issues related to the first stage of any } \\
\text { major change are not addressed in the PERA } \\
\text { handbook. }\end{array}$ & $\begin{array}{l}\text { These issue are central to the CSIRO pro- } \\
\text { posal. }\end{array}$ \\
\hline $\begin{array}{l}\text { Initial EI efforts focus on technology and a } \\
\text { HR plan. }\end{array}$ & $\begin{array}{l}\text { Initial efforts focus on ALL relevant aspects } \\
\text { of organisational resources. }\end{array}$ \\
\hline Obtain / determine Critical Success Factors. & Derive Critical Success Factors. \\
\hline Affirm business strategy. & Support business strategy development. \\
\hline
\end{tabular}


Table 1: Some essential differences between the starting points for change for PERA and the CSIRO proposal.

PERA - Master Plan Development

Assumes availability of business plans, critical success factors, etc.

Generic applicability - applicable to all companies in all industries.

Resultant information systems development tends to focus on the operational level.

Generic list of relevant tools is made available.

To-be analysis precedes as-is.
CSIRO Proposal

Highlights the necessity of planning; fasttrack options are identified as an interim pathway.

Applicability restricted to all manufacturing enterprises to which some form of cellular manufacturing is applicable. The diagnostic capability should be applicable to most manufacturing enterprises.

Resultant information systems should ensure that the innovation and improvement layers (Inagaki, 1993) are also addressed.

Tighter coupling between a range of possible tools and specific activities performed within each phase of the methodology. GRAI-GIM and / or CIM-OSA tools/techniques can also be incorporated.

As-is precedes to-be analysis.

\section{CONCLUSION}

We have argued that successful implementation of Cellular Manufacturing can involve a degree of change comparable to Enterprise Integration, and that as they need to address much the same issues, the problems share a common need for a preparatory phase where the existing manufacturing strategy is assessed and plans for appropriate action are devised. We have suggested that the tools and techniques which we have developed within the context of Cellular Manufacturing could be used in the preparatory phase for Enterprise Integration, and furthermore, that a comprehensive methodology to assess the need for change (and to plan for it) could be constructed.

\section{REFERENCES}

Bemelman, R. \& Jarvis, D.H. (1995), A Successful Cell Design Methodology. Technical Report MTA 354, CSIRO Division of Manufacturing Technology. 
Doumeingts, G., Vallespir, B., Zanettin, M., Chen, D. (1992), GRAI-GIM Integrated Methodology for Designing CIM systems Version 1.0. LAP / GRAI Laboratory, University of Bordeaux I.

Hill, T. (1995), Manufacturing Strategy: The Strategic Management of the Manufacturing Function. Macmillan, London.

Inagaki, K. (1993), The Role of Information Systems Infrastructure in Production Management., Proceedings of DISM '93, Tokyo.

Lamacraft, R.R. and Seabrook, T.D. (1993), Microscheduling of Discrete Manufacturing Operations: What is it; Why Bother. Technical Report MTA 240, CSIRO Division of Manufacturing Technology.

Nemes, L. and Bernus, P. (1994), A Framework to Define a Generic Enterprise Architecture and Methodology - GERAM. Technical Report MTM 366, CSIRO Division of Manufacturing Technology.

Rockart, J.F. (1979), Chief Executives Define Their Own Data Needs. Harvard Business Review, 57, 81-93.

Wells, A.J., Jarvis, D.H., Seabrook, T.D. and Lamacraft, R.R. (1988), An Implementation of Cellular Manufacturing. Proc. 4th. Int. Conf.on Manufacturing Engineering, Brisbane.

Warnecke, H.J. (1993), The Fractal Company: A Revolution In Corporate Culture. SpringerVerlag.

Williams, T.J. (1991), The Purdue Enterprise Reference Architecture. Report No. 154, Purdue Laboratory for Applied Industrial Control.

Williams, T.J. (1994), A Guide To Master Planning And Implementation For Enterprise Integration Programs. Report Number 157, Purdue Laboratory for Applied Industrial Control.

Williams, T.J., Bernus, P., Brosvic, J., Chen, D., Doumeingts, G., Nemes. L., Nevins, J.L., Vallespir, B., Vlietstra, J., Zoetekouw, D. (1994), Architectures for Integrating Manufacturing Activities and Enterprises. Computers in Industry, 24, 111-139.

\section{BIOGRAPHY}

Reini Bemelman is a Manufacturing Systems Specialist at the CSIRO Division of Manufacturing Technology in Adelaide, South Australia. Prior to joining CSIRO, he spent 13 years in the manufacturing industry designing, developing and implementing engineering and manufacturing systems. He has participated in several industry exchange programs in Europe and the U.S.A. He holds a B.Sc. degree, Graduate Management Qualification and is certified in production and inventory management (APICS). His current research interests are cellular manufacturing and enterprise integration. He is a member of BPICS.

Dennis Jarvis is a Principal Research Scientist at the CSIRO Division of Manufacturing Technology in Adelaide, South Australia. He holds a B.Sc. degree from the Flinders University of South Australia, and Dip. Comp. Sci. and Ph.D. degrees from the University of Queensland. His current research interests are in cellular manufacturing, enterprise modelling and modelbased fault diagnosis. He is a member of AAAI 